\title{
Influencias italianas y alemanas en los orígenes del socialismo argentino. Enrico Ferri y Karl Kautsky en las páginas de Vorwärts y La Vanguardia (1894-1895)
}

\section{Italian and German influences on the origins of Argentine socialism. Enrico Ferri and Karl Kautsky in the pages of Vorwärts and La Vanguardia} (1894-1895)

\author{
Lucas Poy * \\ Esteban González Rittler **
}

\begin{abstract}
Resumen: Este artículo analiza el rol que jugó la traducción, publicación y difusión del libro Socialismo y ciencia positiva, de Enrico Ferri, en el proceso de definiciones programáticas del naciente socialismo argentino, a mediados de la década de 1890. Con ese fin, examina un aspecto hasta ahora inexplorado: las diferencias que surgieron entre los editores de La Vanguardia, abiertamente favorables a las interpretaciones de Ferri, y los del Vorwärts, el periódico en idioma alemán que había sido pionero del socialismo local. El artículo revela que la discusión argentina replicaba en buena medida intercambios que tenían lugar en Europa, a partir de los señalamientos críticos hechos por Karl Kautsky al trabajo de Ferri desde las páginas de Die Neue Zeit.
\end{abstract}

Palabras clave: Socialismo; Marxismo; Positivismo; Enrico Ferri; Karl Kautsky; Juan B. Justo

\begin{abstract}
This paper analyzes the role of Enrico Ferri's book, Socialism and Positive Science, in the process of programmatic definitions that shaped Argentine Socialism in the mid-1890s. In so doing, it addresses an aspect until now unexplored: the differences that emerged between the editors of La Vanguardia, openly favorable to Ferri's interpretations, and those of the Vorwärts, the German-language newspaper that had pioneered local socialism. The article reveals that the Argentine discussion
\end{abstract}

\footnotetext{
* Argentino. Doctor en Historia por la Universidad de Buenos Aires. Docente en las facultades de Ciencias Sociales y Filosofía y Letras (UBA), e investigador del CONICET en el Instituto de Historia Argentina y Americana "Dr. Emilio Ravignani"<lucaspoy@gmail.com>

** Argentino. Profesor de Enseñanza Media y Superior en Historia por la Universidad de Buenos Aires. Docente en la facultad de Filosofía y Letras (UBA) <ritgon@gmail.com>
} 
largely replicated exchanges taking place in Europe, after a critical review of Ferri's book published by Karl Kautsky in Die Neue Zeit.

Keywords: Socialism; Marxism; Positivism; Enrico Ferri; Karl Kautsky; Juan B. Justo

Recibido: 01/02/ 2017

Aceptado: 24/05/ 2017

\section{Presentación}

La relación del italiano Enrico Ferri con el socialismo argentino se asocia de manera habitual con el debate que mantuvo con Juan B. Justo, cuando en ocasión de una visita a la Argentina en 1910 puso en cuestión la pertinencia y las condiciones de posibilidad de un movimiento socialista en el país. ${ }^{1}$ La influencia de Ferri en el socialismo local, no obstante, se remonta a la década previa, cuando sus obras jugaron un papel muy destacado en la estructuración teórica y política del programa partidario. En esos años finales del siglo XIX, la expansión de partidos y agrupamientos socialistas en diversos lugares del mundo estaba marcada por un complejo proceso de circulación de libros y folletos de propaganda política, que conformaron constelaciones peculiares de influencias intelectuales que deben ser analizadas en su particularidad. ${ }^{2}$ Distintas investigaciones sobre el socialismo argentino —un área de estudios que en los últimos años ha conocido un desarrollo importante — han abordado aspectos de estos procesos de difusión intelectual en el país, así como la influencia del positivismo en el pensamiento de Juan B. Justo. ${ }^{3}$ Al mismo tiempo, se han

\footnotetext{
${ }^{1}$ Ver, entre otros, Richard Walter, The Socialist Party of Argentina, 1890-1930, Austin, The University of Texas Press, 1977, págs. 65 a 67; Ricardo Martínez Mazzola, "El debate Justo-Ferri y la cuestión de las alianzas políticas", Revista Socialista, núm. 5, 2011, pp. 63-74; Carlos Herrera, "El socialismo argentino frente a Enrico Ferri”, Archivos de historia del movimiento obrero y la izquierda, núm. 6, 2015, pp. 73-94.

${ }^{2}$ Franco Andreucci, "La difusión y vulgarización del marxismo", en Historia del marxismo, Barcelona, Bruguera, 1980; Eric Hobsbawm, "La difusión del marxismo (1890-1905)", en Marxismo e historia social, Puebla, Instituto de Ciencias de la Universidad Autónoma de Puebla, 1983.

${ }^{3}$ La principal referencia respecto a la cuestión de la recepción del marxismo en Argentina, a fines del siglo XIX, es el trabajo de Horacio Tarcus, Marx en la Argentina. Sus primeros lectores obreros, intelectuales y científicos, Buenos Aires, Siglo XXI, 2007. Sobre el pensamiento de Juan B. Justo, algunas obras fundamentales son José Aricó, La hipótesis de Justo: escritos sobre el socialismo en América Latina, Buenos Aires, Sudamericana, 1999; Jorge Dotti, Las vetas del texto. Una lectura filosófica de Alberdi, los positivistas, Juan B. Justo, Buenos Aires, Puntosur, 1990; Patricio Geli, y Leticia Prislei, "Una estrategia socialista para el laberinto argentino. Apuntes sobre el pensamiento político de Juan B. Justo", Entrepasados, núm. 4-5, 1993; Javier Franzé, El concepto de política en Juan B. Justo. Buenos Aires, CEAL, 1993.
} 
realizado algunos avances en torno al papel jugado por los grupos de militantes de origen alemán en ese período temprano de estructuración del socialismo argentino. ${ }^{4}$

Ha sido menos trabajada, sin embargo, la relación problemática, en el plano intelectual, entre estos sectores vinculados a la socialdemocracia alemana y otros dirigentes, como Justo, en esos años decisivos de mediados de la década de 1890. Con la intención de realizar un aporte a la historia intelectual de los orígenes del socialismo argentino, este artículo trabaja un debate que tuvo lugar en las páginas de Vorwärts y La Vanguardia en torno a la recepción de la obra de Enrico Ferri en 1895 y fue virtualmente inexplorado por la historiografía. Buscamos con ello examinar el lugar que ocupó una lectura evolucionista y positivista del desarrollo social en la estrategia política de Justo y el modo en el cual ésta se consolidó a través de la apropiación de algunas obras del socialismo europeo de la época en desmedro de otras.

En primer término, el artículo repasa los rasgos fundamentales de la interpretación y los planteamientos políticos desarrollados por el socialismo argentino en los años centrales de la década de 1890, prestando especial atención a los fuertes elementos evolucionistas y positivistas que lo estructuraban. En segundo término, explora el papel fundamental que tuvo en este contex to la traducción, publicación y difusión de Socialismo y ciencia positiva, de Enrico Ferri, para consolidar estas posturas y respaldarlas con la referencia a un renombrado intelectual de la época. En tercer lugar, el artículo examina un aspecto hasta ahora inexplorado de este proceso de recepción: las diferencias que surgieron entre los editores de La Vanguardia, abiertamente favorables a las interpretaciones de Ferri, y los del Vorwärts, el periódico en idioma alemán que había sido pionero del socialismo local. En buena medida, la discusión argentina replicaba intercambios que tenían lugar en Europa, a partir de los señalamientos críticos hechos por Karl Kautsky al trabajo de Ferri desde las páginas de Die Neue Zeit. El artículo reconstruye los ejes fundamentales de esta crítica a Ferri, examina el alcance y los límites de la discusión en Buenos Aires, en la cual intervino el propio Juan B. Justo, y concluye valorando la importancia de estas reflexiones para la configuración de la táctica y estrategia política del naciente socialismo argentino.

\footnotetext{
${ }^{4}$ Los trabajos clásicos en este terreno son los de José Ratzer, Los marxistas argentinos del 90, Córdoba, Pasado y Presente, 1970; Leonardo Paso (ed.), La clase obrera y el nacimiento del marxismo en la Argentina, Buenos Aires, Testimonios, 1974; y Jan Klima, "La asociación bonaerense Vorwärts en los años ochenta del siglo pasado", Iberoamericana Pragensia. Año VIII, 1974. Más recientemente, la cuestión ha sido revisitada por diferentes investigaciones: ver, por ejemplo, Jessica Zeller, "Entre la tradición y la innovación. La experiencia del Vorwärts en Buenos Aires", Políticas de la memoria, núm. 5, 2007; Horacio Tarcus, Jessica Zeller y Sandra Carreras, Die deutschen Sozialisten und die Anfänge der argentinischen Arbeiterbewegung: Antologie des Vorwärts, (Buenos Aires 1886 - 1901), Buenos Aires, CeDInCI Editores/Buenos Libros, 2008; Alfredo Bauer, La Asociación Vorwärts y la lucha democrática en la Argentina, Buenos Aires, Biblioteca Nacional, 2009; Lucas Poy, y Daniel Gaido, "Under German Eyes: German AveLallemant and the Origins of Marxism in Argentina”, Science \& Society, vol. 75, núm. 4, 2011, pp. 480-505.
} 


\section{La Vanguardia: un programa para el socialismo argentino}

A principios de 1894, el socialismo argentino comenzaba una incipiente recuperación luego del reflujo de los tres años previos, marcados por la crisis económica, el retroceso del movimiento obrero y las dificultades para sostener una actividad política permanente. ${ }^{5}$ De la fragmentaria evidencia disponible es posible reconstruir que el movimiento socialista local no contaba en ese entonces más que con unos dos centenares de militantes, de extracción mayoritariamente obrera, casi en su totalidad varones y concentrados en la ciudad de Buenos Aires. Este universo de militantes tenía un indudable punto de referencia común en la necesidad de impulsar la acción política, pero estaba aún lejos de constituir una organización sólida. La reanimación de la actividad obrera que comenzaba a hacerse evidente en 1894 dio impulso a los grupos socialistas y preparó el terreno para un proceso de crecimiento, expansión y progresiva centralización de la actividad, que culminaría en la celebración de un congreso constituyente a mediados de 1896.

El rasgo decisivo del salto organizativo y político de los grupos socialistas locales que tuvo lugar en ese decisivo bienio fue el rol hegemónico jugado por Juan B. Justo, quien a pesar de haberse incorporado a las actividades del movimiento socialista recién a fines de 1893 mostró, en los años inmediatamente posteriores, una notable capacidad para orientar política y teóricamente al mismo y moldear muchos de los rasgos fundamentales de su pensamiento político. Justo desempeñó este rol a través de La Vanguardia, en tanto durante estos años tuvo un papel protagónico como editor y puso su sello, a través de notas de análisis y editoriales, a una serie de planteamientos teóricos y programáticos fundamentales.

La célebre frase inicial del editorial del primer número de La Vanguardia, en abril de 1894, "este país se transforma", resumía el punto de partida de su planteamiento: por una parte, la constatación de que Argentina se integraba al desarrollo capitalista; por otra, la caracterización del rol positivo que éste jugaba, a nivel internacional y ahora también en el país, como factor de modernización y progreso. Según Justo, el capital se había "enseñoreado del país" y la consecuencia era que se producían "en la sociedad argentina los caracteres de toda sociedad capitalista". Más allá de las penurias a que se veía sometida la clase obrera, el saldo de esta modernización era positivo en la medida en que contribuía a delimitar claramente a "las dos clases, de cuyo antagonismo ha de resultar el progreso social". 6

Desde la perspectiva de Justo, el carácter progresivo de la entrada del país en la modernidad capitalista se veía retrasado por la "ineptitud y rapacidad" de la clase dirigente argentina. Es por ello que las cosas solo cambiarían con la intervención de la clase obrera, que tendría un efecto progresista sobre el conjunto de la sociedad y la política del país. Al organizarse en

\footnotetext{
${ }^{5}$ Ricardo Falcón, “Orígenes del movimiento socialista en Argentina. Prólogo. Capítulo I y II”, Cuadernos del Ciesal, núm. 10, 2011, pp 11-45; Lucas Poy, Los orígenes de la clase obrera argentina. Buenos Aires: Imago Mundi, 2014.

6 "Nuestro programa", La Vanguardia, 7 de abril de 1894.
} 
partido, el proletariado daría "el primer paso importante en el camino de su emancipación, e imprimiría un gran impulso a la evolución histórica de este pueblo", en tanto lograría que la política dejase de ser "el terreno donde se debaten mezquinos intereses de camarilla para ser la liza en que midieran sus fuerzas las antagónicas clases sociales". 7 La tarea inmediata que se planteaba, por lo tanto, era la de continuar con la unificación de las fuerzas de los grupos socialistas: "unir con el lazo federativo a los grupos organizados, fundiendo en un programa común los diversos existentes". 8

Esto fue lo que ocurrió a lo largo de 1894 y 1895, un período en el cual la centralización organizativa se combinó, en las páginas de La Vanguardia, con la definición de un programa. La caracterización desarrollada sobre las particularidades del país daba lugar, en este punto, a una perspectiva de acción que debía centrarse en la lucha por reformas. Si bien consideraba que el programa no diferiría demasiado del de los partidos de Europa y Estados Unidos, en tanto "en todas partes las consecuencias del capitalismo son esencialmente las mismas, como lo son también los reclamos más perentorios del proletariado", La Vanguardia admitía que el mismo debía tener en cuenta "las circunstancias locales, y la dirección que ellas deben imprimir a nuestra conducta política". 9 En tanto la naciente organización política tenía lugar "en una región cuyo desarrollo económico es todavía muy incompleto, y cuyas prácticas políticas son semi-bárbaras", se planteaba explícitamente que "la acción revolucionaria del partido socialista es y será tal vez por muchos años completamente utópica". ${ }^{10}$

En la editorial del primer número, de hecho, Justo había evitado hacer referencia a las aspiraciones últimas de superación de la sociedad capitalista y se limitó a decir que el objetivo era "representar en la prensa al proletariado inteligente y sensato" y "promover todas las reformas tendentes a mejorar la situación de la clase trabajadora", como la jornada de ocho horas, la supresión de los impuestos indirectos, la protección de mujeres y niños, "y demás partes del programa mínimo del partido internacional obrero". Al mismo tiempo, se aclaraba que su objetivo era "fomentar la acción política del elemento trabajador argentino y extranjero como único medio de obtener esas reformas". El nuevo periódico recordaba que venía "a difundir las doctrinas económicas creadas por Adam Smith, Ricardo y Marx, a presentar las cosas como son, y a preparar entre nosotros la gran transformación social que se acerca". ${ }^{11}$

Este peculiar eclecticismo en las referencias teóricas sería en efecto un rasgo característico del pensamiento de Justo y del socialismo argentino: como veremos en este trabajo, no se trataba de todas formas de una originalidad local. La división de la sociedad entre burgueses y proletarios y el desarrollo de la lucha de clases, elementos subrayados una y

\footnotetext{
7 "Plutocracia criolla", La Vanguardia, 1 de septiembre de 1894.

8 “El Partido Socialista en Buenos Aires", La Vanguardia, 23 de junio de 1894.

9 ídem

10 "Los socialistas en la política argentina", La Vanguardia, 26 de mayo de 1894.

11 "Nuestro programa", op.cit.
} 
otra vez en La Vanguardia de la época, eran decodificados en la mirada de Justo en una clave civilizatoria, marcada por influencias biologicistas y positivistas. Una editorial publicada el 1 de mayo, por ejemplo, advertía que los trabajadores no tenían Dios ni debían adular a un ser supremo; tampoco tenían interés en la "baja preocupación patriótica", dado que su patria no tenía fronteras. En sus fiestas, en su programa, en su táctica y "también en su acción revolucionaria cuando llegue el momento", el proletariado militante era en cambio "originariamente positivo y científico" y estaba "imbuido del gran principio biológico de la lucha por la vida, representada en las sociedades humanas por la lucha de clases". 12

En este marco, se entendía que la acción política y la acción parlamentaria jugaban un rol educador de la clase obrera: la lucha por las reformas y la organización de las fuerzas socialistas en el marco de la sociedad capitalista eran vistos como un paso necesario y como la única tarea concreta que podía plantearse en el horizonte inmediato. Los socialistas argentinos de la época aún reconocían que, en última instancia, sus fines "no se verán cumplidos sino abatiendo primero por la fuerza brutal el predominio de la burguesía" pero sabían al mismo tiempo que ello debía "hallar los ejecutores y el terreno preparado". Por eso participaban en la lucha electoral y desarrollaban una tarea de educación de los trabajadores, "para preparar la revolución y crear la fuerza que ha de llevarla a cabo". ${ }^{13}$

\section{Enrico Ferri, una influencia decisiva}

A lo largo de 1895, esta lectura evolucionista y gradualista se consolidó y ganó en densidad. Un papel clave, en este contexto, le cupo a Socialismo y ciencia positiva, un folleto de Enrico Ferri que apareció en Italia en 1894 y fue publicado en Buenos Aires un año más tarde con traducción e introducción de un joven Roberto J. Payró, que acababa de acercarse al socialismo. La lectura evolucionista de Ferri empalmaba con las caracterizaciones que se venían desarrollando en las páginas de La Vanguardia, y aportó al socialismo local un respaldo intelectual, con un fuerte barniz cientificista, para la consolidación de un planteamiento que enfatizaba el carácter gradual y pacífico de la perspectiva socialista. ${ }^{14}$ Era la primera vez que se traducía en Argentina una obra del

\footnotetext{
12 "El 1 de Mayo y la jornada de ocho horas", La Vanguardia, 1 de mayo de 1894.

13 "La política: cómo la entiende el Partido Socialista", La Vanguardia, 24 de noviembre de 1894.

${ }^{14}$ Según Tarcus, "en el marco de la cultura obrera de fin de siglo, con su fuerte sesgo cientificista, la afiliación en 1893 al Partido Socialista Italiano de un científico reputado como Enrico Ferri era interpretada por la mayoría con una reafirmación de la verdad doctrinaria y de la corrección de la senda política emprendida". A eso se agregaba que Ferri escribía en un lenguaje accesible y sintetizaba "marxismo y darwinismo, socialismo y positivismo (...) determinismo biológico y determinismo económico" (Horacio Tarcus, Marx en la Argentina, Buenos Aires, Siglo XXI, 2007, pág. 328). Tarcus destaca que, a pesar de que había traductores del alemán en el equipo de redacción de La Vanguardia, "en el trayecto que va del Verein Vorwärts al Partido Socialista resulta claro que la política de traducciones se desplazaba del socialismo alemán al socialismo de los países latinos”, particularmente al italiano (ídem, pág. 327). El autor señala que fue a través de autores como Ferri y Loria, antes que por Bernstein, como penetraron en Argentina "concepciones identificadas con el 'revisionismo' y el 'reformismo", pero destaca que "esta 'contaminación' ya estaba abonada por el
} 
socialismo internacional de la magnitud de un libro, y si bien la publicación fue parte de las iniciativas del grupo de estudiantes nucleados en el recién creado Centro Socialista Universitario, su difusión fue ampliamente alentada desde las páginas de La Vanguardia, a punto tal que se convirtió en uno de los libros fundantes de la cultura política del socialismo argentino. ${ }^{15}$ El folleto costaba $\$ 1,50$ pero su valor se reducía a $\$ 1,20$ para miembros del partido; según Tarcus, la primera edición podría haber alcanzado los mil ejemplares, y en 1904 se realizó una segunda tirada que elevó esa cifra a cinco mil. ${ }^{16}$

Socialismo e scienza positiva (Darwin-Spencer-Marx) era un folleto de unas 170 páginas, publicado en Roma por la Casa Editrice Italiana en 1894 y firmado por "Enrico Ferri, deputato al Parlamento". En ese momento Ferri no se había convertido todavía en una figura de la envergadura que tendría en la década siguiente, cuando realizó varias visitas a la Argentina, pero ya era un destacado intelectual, académico, científico y parlamentario, así como un importante referente del naciente socialismo italiano. Había nacido en 1856 en una pequeña localidad de la provincia de Mantova, en el valle del río Po, y alcanzó notoriedad pública a mediados de la década de 1880, cuando encaró la defensa legal de los campesinos mantovanos que se habían declarado en huelga y obtuvo una amplia popularidad en la zona, lo cual le permitió ser electo como diputado en 1886. La suya era, en este período, una trayectoria con paralelismos con la de Jean Jaurès: universitarios de orientación radical que se vincularon con sectores del movimiento obrero y alcanzaron un lugar en el parlamento, antes de integrarse orgánicamente a organizaciones socialistas. En esa primera etapa de su vida política, de acuerdo con Rinaldo Salvadori, la acción de Ferri se basaba "en vagos principios de solidaridad humana, de confianza exclusiva en las cooperativas para la solución de la cuestión social y de rechazo de la lucha de resistencia". ${ }^{17}$

Una segunda etapa se inició cuando Ferri se unió al nuevo Partido Socialista Italiano en su congreso de Reggio Emilia, en septiembre de 1893: ya en esa ocasión se cruzó en una polémica con Filippo Turati, criticando la "intransigencia" partidaria y defendiendo un

marxismo fuertemente objetivista y cientificista de un Lallemant o un Justo". Más adelante Tarcus reconoce, de todos modos, que esta recepción fue resistida por Lallemant, quien "hacía gala de una ortodoxia marxista que dejaba indiferente a Justo", y que las reivindicaciones de Ferri publicadas por La Vanguardia se inscribían "implícitamente en un campo de debates previo, pues muchos marxistas europeos — de los que se hace eco Lallemant—se resisten a las amalgamas teóricas de Ferri" (ídem, págs. 327-328). El debate reconstruido en este artículo desenvuelve el modo en el cual estas discusiones europeas repercutieron en las filas del socialismo local y permite advertir las líneas de tensión que existían entre el equipo de redacción de La Vanguardia, liderado por Justo, y los socialistas alemanes que editaban el Vorwärts, mucho más cercanos a las ideas de Lallemant y de la socialdemocracia alemana.

${ }^{15}$ Las agrupaciones socialistas de Buenos Aires ya habían comenzado a difundir obras y folletos de diversos autores del movimiento socialista internacional, editados en Italia o en España, en los años previos. También habían realizado una edición propia del Manifiesto Comunista en 1893, basada en la traducción española de José Mesa de 1872 (Tarcus, op.cit., págs. 302-303). Era habitual, asimismo, que se publicaran extractos de folletos o artículos de socialistas extranjeros, en ocasiones traducidos en Argentina de las versiones en italiano, en las páginas de La Vanguardia.

16 Tarcus, op.cit., pág. 335.

${ }^{17}$ Rinaldo Salvadori, La repubblica socialista mantovana. Da Belfiore al fascismo. Milán, Del Gallo, 1966, pág. 221. (Todas las traducciones de textos en otros idiomas son propias). 
"método gradual", pero aceptó someterse a la disciplina y la vida interna del partido. En esos años Ferri fundó una revista, La scuola positiva nella giurisprudenzia civile e penale e nella vita sociale, y profundizó el contenido 'científico' de su adhesión al socialismo. La publicación de Socialismo y ciencia positiva, que en buena medida retomaba muchos de los argumentos desarrollados una década antes en su Socialismo e criminalitá de 1883, coronaba esta nueva etapa de su trayectoria. ${ }^{18}$

En su introducción a los lectores locales, Roberto Payró destacaba que, más allá de algunos aspectos menores, el análisis que hacía Ferri era plenamente aplicable al caso argentino, en tanto el país estaba integrado a un proceso de transformaciones que ponía a la orden del día la acción de los socialistas. Socialismo era sinónimo de modernidad, y Argentina estaba en ese camino, aun cuando todavía pocos lo advirtiesen: la aparición y consolidación de agrupaciones socialistas y de organizaciones obreras eran un síntoma de este desarrollo. Payró se esforzaba por dejar claro que el libro mostraba el carácter no violento, gradual y reformista, a la vez que científico, que había adquirido ese movimiento socialista que llegaba al país. Se advertían, en este punto, las presiones sufridas por un núcleo de jóvenes estudiantes por parte de sectores de su propia extracción social, fuertemente hostiles al socialismo pero afines al discurso científico de la época: ${ }^{19}$ según Payró, entre los méritos del libro estaba el de dar "una clarísima explicación de lo que es el socialismo marxista" y desvanecer "los temores que despierta en ciertos espíritus la creencia de que el socialismo marchará a la conquista de su ideal político con las armas en la mano". Entendía que el libro demostraba "de una manera clara, terminante y fructífera" que el movimiento socialista no era "el espasmo epiléptico de una humanidad enferma, sino la marcha gradual, acusada por síntomas a veces sobresaltados, de una evolución inevitable y lógica, que podrá prolongarse, pero que llegará necesariamente a su fin". ${ }^{20}$

Además de difundir en forma sistemática el folleto de Ferri, que estaba a la venta en el local partidario, La Vanguardia publicó algunos extractos de la sección titulada "Evolución, revolución, rebelión, violencias personales. Socialismo y anarquía". ${ }^{21}$ Los socialistas argentinos buscaban así ampararse en un autor reconocido como Ferri para reforzar una interpretación que veía a la reivindicación del elemento científico aportado por Marx como una confirmación de que sus planteos iban en línea con el propio desarrollo y evolución "naturales" de la sociedad. En consecuencia, la crítica a los anarquistas —y a los métodos violentos - era planteada en términos similares a la crítica a los socialistas utópicos, de los

18 "La exitosísima carrera académica de Ferri, su imagen de científico famoso, el rol de privilegio que jugó en un mucho de los principales casos judiciales (...) constituyeron una suerte de trampolín también para la afirmación de Ferri al interior del PSI" (Franco Andreucci y Tomasso Detti, Il movimento operaio italiano: dizionario biografico, $1853-1943$. Roma, Riuniti, 1975, págs. 344-346).

${ }^{19}$ Acerca de los vínculos intelectuales y sociales entre la intelectualidad reformista liberal y los jóvenes universitarios socialistas, ver Eduardo Zimmermann, Los liberales reformistas. La cuestión social en la Argentina, 1890-1916, Buenos Aires, Sudamericana, 1995, págs. 58-60.

${ }^{20}$ Enrico Ferri, Socialismo y ciencia positiva: Darwin, Spencer, Marx (traducción de Roberto J. Payró), Buenos Aires: Imprenta de la Nación, 1895, pág. V.

21 "La lucha de clases", La Vanguardia, 1 de junio de 1895. 
cuales aquellos eran vistos como continuadores. Según Ferri, el socialismo antes de Marx "no era más que la expresión sentimental de un humanitarismo tan generoso cuanto careciente de los más elementales principios del positivismo científico" y por ello era comprensible que "sus secuaces o defensores cedieran fácilmente a los impulsos del corazón". 22

Razonamientos de este tipo eran comunes al conjunto de la socialdemocracia de la época, e incluso el socialista alemán Germán Ave-Lallemant había desarrollado ideas similares algunos años antes en una polémica con militantes anarquistas. ${ }^{23}$ Pero el libro de Ferri llevaba este argumento a un maridaje directo con las teorías positivistas y evolucionistas, configurando una interpretación que estaría en la matriz del socialismo argentino y que en este punto, como veremos, se contraponía con los planteos de Lallemant y otros socialistas alemanes. Según el autor italiano,

... el socialismo científico representa una fase mucho más avanzada de las ideas socialistas, de acuerdo precisamente con la ciencia positiva moderna $-\mathrm{y}$ ha abandonado por completo la fantástica idea de profetizar hoy lo que será la sociedad humana en la nueva organización colectiva. Lo que el socialismo científico puede afirmar y afirma, con seguridad matemática, es que la dirección, la trayectoria de la evolución humana, marcha en el sentido general indicado y previsto por el socialismo, es decir, en el sentido de una continua y progresiva preponderancia de los intereses y las utilidades de la especie, sobre los intereses y utilidades del individuo, y por consiguiente en el sentido de la continua socialización de la vida económica y por ella de la vida jurídica, moral y política que de ella dependen". ${ }^{24}$

La evolución y la revolución, en este análisis, no aparecían como fenómenos contradictorios sino complementarios, en un esquema evolutivo. Podía comprenderse la impulsividad y el arrebato violento en los trabajadores, pero esa no era de ningún modo la táctica de la socialdemocracia. De acuerdo con Ferri,

... los procesos normales (...) de transformación social son la evolución y la revolución, entendida esta última en el sentido exacto y positivo de fase última de una evolución anterior, y no convirtiéndola en sinónimo de una rebelión tumultuosa y violenta como por lo común se piensa equivocadamente. ${ }^{25}$

Es interesante advertir que Ferri consideraba que no existía una contradicción entre estos planteos y la ortodoxia marxista de la socialdemocracia alemana. El dirigente italiano planteaba explícitamente que "la táctica del socialismo científico, especialmente en Alemania por la influencia más directa del marxismo", había abandonado los "viejos métodos del romanticismo revolucionario, que repetidos tantas veces han abortado siempre y son por eso, en sustancia, menos temidos por las clases dominantes". El punto decisivo

\footnotetext{
${ }^{22}$ Ferri, op.cit., págs. 122-123.

23 Tarcus, op.cit., págs. 219-224; Lucas Poy y Daniel Gaido, op.cit.

${ }^{24}$ Ferri, op.cit., págs. 125-126.

${ }^{25}$ Ibíd., pág. 135.
} 
era que la teoría socialista aparecía como capaz de proporcionar una clave científica para comprender el desarrollo de las sociedades contemporáneas. ${ }^{26}$ Según Ferri,

... el socialismo científico es revolucionario en el sentido científico de la palabra, y se desenvuelve ahora en plena revolución social (...) Y el socialismo marxista tiene la franqueza de decir, por boca de sus representantes más cultos, a la gran falange dolorosa del proletariado moderno, que no tiene la varita mágica para cambiar el mundo de un día para otro como se cambian la decoraciones de teatro al levantar el telón; pero dice también (...) que la revolución social no puede llegar a su término si antes no se ha madurado en la conciencia de los trabajadores mismos, con la visión clara de sus intereses de clase y de su fuerza inmanente cuando están unidos, y no con la creencia de poder despertar un día en pleno régimen socialista". ${ }^{27}$

Ferri planteaba que "el socialismo marxista de todos los países" había planteado que "el medio principal de transformación social debe ser la conquista de los poderes públicos (en las administraciones locales y en los parlamentos), como uno de los efectos de la organización consciente de los trabajadores en un solo partido de clase". Mientras más avanzara esta organización, tanto más se realizaría, "por evolución fatal, la organización socialista de la sociedad, primero con las concesiones parciales pero cada vez más amplias de la clase capitalista a la clase trabajadora (ejemplo elocuente: la ley de las 8 horas) y después la transformación completa de la propiedad individual en propiedad social". Ferri recordaba que "nadie podía profetizar" si esa transformación se realizaría "con o sin el concurso de los demás medios de transformación-rebelión y violencia personal". La aspiración de los socialistas era que la revolución se realizara cuando estuviera "madura la evolución, pacíficamente, como tantas otras revoluciones que se han hecho en paz, sin derramar una gota de sangre". ${ }^{28}$

La reivindicación de las ideas de Ferri, en esta etapa, era compartida por el núcleo activo en la edición de La Vanguardia: su difusión tuvo lugar en los meses en que Justo se encontraba fuera del país, de viaje por Europa y los Estados Unidos, y contó con un importante aporte de Eduardo García, un dirigente que luego de abandonar las filas socialistas se convertiría en un destacado referente del anarquismo argentino, utilizando su segundo apellido: Gilimón. A fines de junio de 1895, García publicó una extensa reivindicación de la obra de Ferri y no ahorró elogios para lo que consideraba un libro "trascendental", que "reasume las teorías marxistas, destruye cuantas objeciones se hacen al socialismo (...) analiza la ciencia moderna, hija de la experimentación, y demuestra la concordancia que existe entre el colectivismo y ella". Según García, Darwin y Spencer habían sido "los fundadores de nuestras ideas", en tanto habían mostrado "el encadenamiento, la evolución de los sucesos de la humanidad", mientras que le había

\footnotetext{
${ }^{26}$ Ver en este punto Jacy Alves de Seixas, Mémoire et oubli: anarchisme et syndicalisme révolutionnaire au Brésil, mythe et histoire. Paris: Éd. de la Maison des sciences de l'homme, 1992, pág. 91.

${ }^{27}$ Ferri, op.cit., págs. 138-139.

${ }^{28}$ Ibíd., págs. 146-148.
} 
tocado a Marx sacar las consecuencias necesarias y crear las teorías socialistas, formando así "la trinidad de que debemos tomar nuestros argumentos para combatir a la burguesía". 29

\section{Las críticas de la socialdemocracia alemana: Kautsky en Die Neue Zeit}

Lo cierto es que la obra de Ferri no recibía la misma evaluación favorable por parte de todos los sectores de la socialdemocracia internacional: unos pocos meses antes, en febrero de 1895, el mismo Karl Kautsky había publicado una fuerte crítica en las páginas de Die Neue Zeit, el más prestigioso órgano teórico de la tradición marxista. ${ }^{30}$ La obra de Ferri había alcanzado una importante difusión, y pronto apareció una versión en alemán que dio lugar a la reseña de Kautsky: la traducción realizada en Argentina y el debate promovido por su obra se insertaban así, en realidad, en un contexto más amplio de circulación de la obra de Ferri al interior de los círculos de la socialdemocracia y de otros sectores intelectuales. ${ }^{31}$ En la medida en que los señalamientos hechos por Kautsky iban a ser leídos en nuestro país, donde no solo circulaba Die Neue Zeit sino que también existía un órgano socialista en idioma alemán y una tradición de más de una década de militancia organizada de los socialistas de esa nacionalidad, resulta importante detenernos en los ejes fundamentales de la crítica kautskiana a la obra del socialista italiano.

El vínculo entre Kautsky y el darwinismo ha ocupado un lugar destacado en las interpretaciones sobre el pensamiento de este teórico socialista, fundamentalmente a partir de la mirada crítica que sobre él trazaron pensadores de la primera posguerra como Karl Korsch y Erich Matthias. Paul Blackledge señala que la crítica al "kautskismo" como una línea política fuertemente marcada por el evolucionismo y el gradualismo fue un rasgo característico de las lecturas políticas e historiográficas realizadas en el siglo XX, durante el cual el "marxismo occidental" procesó un giro "voluntarista" que ponía en cuestión la lectura "objetivista" de Kautsky y la Segunda Internacional. ${ }^{32}$ En ocasión de la fundación de Die Neue Zeit, Kautsky le había pedido a Engels un artículo sobre Darwin: según le señalaba en una carta personal, "no se me ocurre un mejor artículo introductorio para una revista mensual popular que uno sobre Darwin. El nombre mismo ya es todo un programa". ${ }^{33}$ Leszek Kolakowski, por su parte, ha señalado que Kautsky "no era un 'darwinista social' en el sentido de negar el carácter específico de la sociedad humana o reducir los conflictos sociales y las luchas de clases a una mera lucha por la supervivencia

\footnotetext{
29 "Socialismo y ciencia positiva, por Enrique Ferri”, La Vanguardia, 22 de junio de 1895.

${ }^{30}$ Karl Kautsky, "Marxismus und Darwinismus", Die Neue Zeit, vol. 13 (tomo 1), núm. 23, 1895, pp. 709-716.

${ }^{31}$ El libro fue traducido al español, alemán y francés al año siguiente de su aparición. Una versión en inglés fue publicada en Estados Unidos en 1901. Ver David Stack, The First Darwinian Left. Socialism and Darwinism, 1859-1914, Cheltenham, New Clarion Press, 2013, pág. 104.

${ }^{32}$ Paul Blackledge, "Historical Materialism: from Social Evolution to Revolutionary Politics", en Paul Blackledge y Graeme Kirkpatrick, Historical Materialism and Social Evolution, New York, Palgrave Macmillan, 2002.

${ }^{33}$ Citado en Richard Weikart, Socialist Darwinism: Evolution in German Socialist Thought from Marx to Bernstein, San Francisco, International Scholars Publications, 1998, pág. 157..
} 
darwiniana" pero que "sus reservas en cuanto a la reducción de la sociedad humana al nivel de las comunidades animales son mucho menos importantes que las analogías que sí traza entre ellas". 34

Los rasgos comunes entre las ideas darwinistas y la perspectiva teórica y política de Kautsky, no obstante, no deben hacer perder de vista los matices y la complejidad de su pensamiento: en este sentido, la reseña crítica del libro de Ferri — cuyo título, de hecho, era "Marxismo y darwinismo" - resulta una fuente clave para entender el modo en que el teórico alemán entendía la relación entre sus ideas y las del biólogo más reconocido de la época. En el artículo, por cierto, Kautsky partía de reconocer que no era nuevo el paralelismo entre Darwin y Marx y admitía que "la analogía entre las teorías de ambos" era "evidente": tanto uno como el otro habían "encontrado la clave de la evolución en la lucha; Darwin en la lucha por la existencia, Marx en la lucha de clases". ${ }^{35}$ A partir de allí, sin embargo, comenzaban las críticas. Según Kautsky, Ferri había ido demasiado lejos al plantear que el marxismo no era más que la continuación "lógica y necesaria" del darwinismo. Su artículo estaba dedicado a polemizar con esta idea y por lo tanto a mostrar las diferencias entre las teorías de ambos.

Kautsky recordaba, en primer término, que considerar al marxismo como una mera continuación del darwinismo era un error en términos históricos, toda vez que la obra fundamental de Darwin databa de 1857 y Marx ya había expuesto los ejes centrales de su interpretación de la historia en la década previa. Kautsky consideraba que no era Marx sino Spencer quien había basado su obra en la de Darwin y que era por lo tanto un error asimilar las ideas spencerianas con las de Marx; en realidad, ambos estaban "en contraposición no solo con respecto a los resultados a los que arriban sino también al método". ${ }^{36}$

Un primer error cometido por Ferri era considerar que el socialismo era una necesidad producto de una "ley natural". Según Kautsky, el marxismo mostraba que "cualquier forma de sociedad que haya existido, alguna vez fue necesaria, que a los distintos y sucesivos modos de producción corresponden diferentes formas de sociedad". En consecuencia, "querer demostrar que el socialismo es necesario no por determinadas condiciones históricas sino por una ley natural, significa todo menos pensar de manera marxista”. En la misma línea, Kautsky también cuestionaba la pretensión de hablar de la sociedad como un "organismo vivo" y el intento de trasladar al análisis social las leyes propias de la naturaleza. ${ }^{37}$

Kautsky abordaba así el siempre espinoso problema de la relación entre evolución y revolución, un tema decisivo en los debates de la socialdemocracia en esos años y en los

\footnotetext{
${ }^{34}$ Leszek Kolakowski, Main Currents of Marxism: Its Rise, Growth, and Dissolution, Oxford, Clarendon Press, 1978, pág. 36.

${ }^{35}$ Kautsky, op.cit., pág. 709.

${ }^{36}$ Ibíd.

${ }^{37}$ Ibíd., pág. 710.
} 
inmediatamente posteriores. Según Kautsky, "la evolución no excluye a la revolución", sino que era "solamente una fase especial, una forma particular de evolución que surge bajo condiciones determinadas". ${ }^{38}$ El teórico alemán defendía así una interpretación que tenía, en la práctica, numerosos puntos en común con la de Ferri — en tanto buscaba subrayar la complementariedad entre los planteos reformistas de la socialdemocracia y su perspectiva revolucionaria en última instancia- pero que al mismo tiempo cuestionaba los componentes biologicistas y positivistas de la lectura hecha por el socialista italiano:

La evolución social es ante todo el resultado de las luchas en la sociedad. Si hoy la socialdemocracia descarta el levantamiento y los atentados contra personas individuales, lo hace porque las condiciones sociales y políticas históricamente determinadas los volvieron ineficaces y porque remite al proletariado a otras formas más eficaces: huelgas, boicots, campañas electorales, luchas parlamentarias y semejantes; no porque "evolución y revolución sean fisiológicos" y levantamientos y atentados "patológicos" (...) Hubo situaciones históricas, en las cuales levantamientos o actos de violencia contra individuos fueron métodos muy eficaces de la lucha de clases, de la "evolución y la revolución". ${ }^{39}$

Kautsky planteaba incluso que "ni siquiera le queremos reconocer a Ferri que la lucha personal sea "individualista", que la socialdemocracia no luche contra individuos particulares, sino solamente contra el sistema". En las luchas políticas y económicas, según Kautsky, no se enfrentaban "sistemas o intereses sino personas como portadoras de sistemas e intereses". Era imposible "transformar una monarquía en una república sin destituir a un monarca", del mismo modo que no se podía "reemplazar el sistema capitalista por el socialista, sin expropiar a los capitalistas". ${ }^{40}$

Sobre el final del artículo, Kautsky avanzaba en un intento de caracterización de los motivos que llevaban a figuras como Ferri a desarrollar una perspectiva semejante. Subrayaba que el libro de Ferri no era una mera "manifestación aislada": antes bien, entendía que su punto de vista estaba "bastante extendido fuera de Alemania" y caracterizaba que se trataba de "un signo del estadio de transición en el cual actualmente se encuentran varios partidos socialistas afuera de Alemania". Para Kautsky, la socialdemocracia alemana era el exponente más avanzado del pensamiento socialista: sus principios eran los del Manifiesto Comunista y habían "superado esencialmente todas las formas previas del socialismo y del movimiento obrero en Europa". Los partidos socialistas y obreros de otros países marchaban, es cierto, "en la misma dirección junto con la socialdemocracia alemana", como lo ponían de manifiesto los últimos congresos internaciones: sin embargo, la práctica de esos partidos se había "transformado más rápidamente que sus teorías". Desde la perspectiva de Kautsky, esto no hacía sino confirmar la interpretación materialista de la historia, en la medida en que "la transformación de las ideas es consecuencia de la transformación de las cosas, y no a la

\footnotetext{
${ }^{38}$ Ibíd., pág. 712.

${ }^{39}$ Ibíd.

${ }^{40}$ Ibíd., pág. 713.
} 
inversa". En otros términos, el desarrollo práctico de la organización obrera había puesto a los partidos socialistas de otros países en la misma senda de la socialdemocracia alemana, pero el desarrollo intelectual avanzaba más lento: "las nuevas ideas, correspondientes a las nuevas prácticas, se injertan sobre viejas formas de pensar, generando así un eclecticismo que solo poco a poco es reemplazado por una concepción unificada". ${ }^{41}$

Kautsky iba incluso más allá, introduciendo algunos elementos vinculados a los contextos sociales de producción que serían retomados en el debate argentino. La difusión de este "eclecticismo" a nivel teórico, desde su punto de vista, no se debía solamente al desacople en los tiempos relativos de la expansión organizativa y sus respectivos desarrollos teóricos, sino que había sido promovida, además, por el hecho de que fuera de Alemania se había dado "el paso al socialismo de algunos burgueses cultos, quienes de ninguna manera estaban siempre en condiciones de despojarse inmediata y completamente de los restos de una ciencia burguesa de la que recientemente habían emergido". Kautsky mencionaba como ejemplos a figuras de la Sociedad Fabiana, en Inglaterra, a los partidarios de Benoît Malon, en "los países latinos", y a la figura de Achille Loria, quien había sido duramente criticado por el propio Engels, en Italia. ${ }^{42}$ Kautsky destacaba que era "el señor Loria" quien había "infectado a Ferri con marxismo", tal como el mismo lo ponía de manifiesto en su libro. Al mismo tiempo, observaba que Ferri parecía "haber permanecido ajeno a la mayoría de los escritos de Engels, especialmente a su polémica con Dühring” y lamentaba la poca circulación de ese trabajo en otras lenguas fuera del alemán. ${ }^{43}$

En suma, el artículo de Kautsky ofrecía no solo una crítica al libro de Ferri sino también una particular caracterización acerca del problema de la circulación y difusión de las ideas socialistas en el período. Su conclusión era que, a pesar de la creciente influencia de la socialdemocracia alemana sobre el movimiento socialista y obrero que crecía en Europa y en otras partes del mundo, la asimilación de las ideas marxistas avanzaba de manera más lenta. En sus palabras, "los resultados de las investigaciones de Marx y Engels fueron universalmente aceptados, pero su fundamentación frecuentemente asimilada de manera insatisfactoria, el número de marxistas consecuentes reducido". Según Kautsky, "el grado en el cual estaba difundido el eclecticismo" en la propia Alemania quedaba de manifiesto en el programa de Gotha y en la influencia de Dühring: recordaba que recién a partir de la crítica de Engels habían logrado "comprender completamente a Marx e interpretarlo uniformemente" y que el modo en que desde entonces la socialdemocracia alemana "comenzó a acabar con todos los restos de pensamiento utopista, socialista de cátedra, democrático-burgués" solo podía ser atestiguado por aquel que hubiera "participado de este proceso". A pesar de todo, el tono general de la conclusión del artículo era positivo: más allá de las limitaciones teóricas, lo importante era que se estaba desarrollando un

\footnotetext{
${ }^{41}$ Ibíd., págs. 713-714.

42 Ver el prefacio de Engels al tercer tomo de El Capital. Disponible online en: <https://www.marxists.org/archive/marx/works/1894-c3/pref.htm>

${ }^{43}$ Kautsky, op.cit., págs. 714-715.
} 
movimiento en todos los países. El libro de Ferri estaba "redactado de manera cautivante, llena de fuego y espíritu, en ocasiones fascinante" y era según Kautsky "un brillante alegato al socialismo - aunque no, como considera el autor, al marxismo, pero sí a una significativa fase evolutiva del socialismo italiano que se le aproxima". ${ }^{4}$

\section{Una crítica porteña con acento alemán: el Vorwärts de Buenos Aires}

El Verein Vorwärts y su periódico jugaron un papel importante en los orígenes del movimiento obrero de Buenos Aires, particularmente durante la coyuntura decisiva de 1888-1890, cuando se constituyeron en una pieza clave de los avances organizativos de la clase trabajadora en un contexto de creciente agitación huelguística. En los años posteriores, la importancia relativa del Vorwärts se redujo a medida que crecían y se organizaban otras organizaciones obreras y socialistas: en ese marco el Verein se recostó algo más en las actividades culturales y asociativas en el seno de la comunidad alemana y su peso político en el marco del naciente partido disminuyó. No obstante, en 1895 su periódico continuaba publicándose en forma semanal y el grupo, con sus más de cien miembros, aún constituía en la práctica uno de los centros socialistas más importantes, tanto en términos numéricos como financieros.

Si bien las relaciones entre los grupos eran cordiales y en esa época el Verein Vorwärts participaba en forma habitual en reuniones y actos convocados por las agrupaciones socialistas de la ciudad, existían también cruces y tensiones entre los socialistas alemanes y otros sectores activos en el naciente partido. En especial, el Vorwärts no ocultaba sus diferencias con los jóvenes universitarios que habían constituido el Centro Socialista Universitario a fines de 1894: como veremos, este recelo hacia los intelectuales y profesionales que manifestaban simpatías con los socialistas estaba directamente relacionado con toda una tradición política de la socialdemocracia alemana. El 14 de septiembre de 1895, por ejemplo, estas tensiones llegaron a las páginas de La Vanguardia, cuando se publicó una "carta abierta" firmada por José Ingegnieros en nombre del CSU. Allí se criticaba al socialista alemán Augusto Kühn por haber planteado, en el Vorwärts, que "exceptuados unos cuantos buenos socialistas", en el CSU la mayoría entendía y profesaba "un socialismo a su manera". Ingegnieros consideraba la acusación de Kühn como "calumniosa" y lo invitaba a desarrollar sus argumentaciones. Concluía ironizando que, después de escucharlo, los socialistas del CSU estarían en condiciones "de solicitar, donde él la habrá sin duda solicitado, una patente que nos acredite como verdaderos socialistas; patente que según suponemos traerá los sellos y firmas de los magnos pontífices a que sin duda obedecen el señor K.n y sus congéneres". 45

\footnotetext{
${ }^{44}$ Ibíd., págs. 715-716.

45 "Carta abierta", La Vanguardia, 14 de septiembre de 1895. Sobre los puntos en común entre los primeros escritos de Ingenieros y los planteamientos de Ferri, ver Tarcus, Marx en la Argentina, op.cit., pág. 240. Al año siguiente continuaban las críticas del Vorwärts al CSU: ver, por ejemplo, "Was sollen wir also thun?", Vorwärts, núm. 478, 21 de marzo de 1896.
} 
La discusión sobre el folleto de Ferri se planteaba, por lo tanto, sobre este terreno de tensiones y recelos entre el grupo de socialistas alemanes, estrechamente vinculado al SPD de su país, y el grupo de jóvenes intelectuales argentinos que se volcaban al socialismo y obtenían una creciente influencia en la todavía débil estructura partidaria. La realidad era que la crítica de Kautsky, publicada en febrero, no había sido siquiera comentada por La Vanguardia, que en cambio venía difundiendo ampliamente el folleto y las ideas de Ferri y Loria. ${ }^{46}$ Así las cosas, el 19 de octubre de 1895 el Vorwärts salió a la palestra con una crítica muy dura, no solo al libro de Ferri sino a la iniciativa de los socialistas argentinos de traducirlo y difundirlo. El Vorwärts cuestionaba que, a través de la traducción, Payró se hubiese ocupado de "dar a conocer las teorías de Spencer a amplios círculos de la burguesía" y que también La Vanguardia hubiera "realizado el máximo esfuerzo para proporcionarle un público" al folleto. Los socialistas alemanes de Buenos Aires destacaban que "el libro de Payró" había encontrado "una amplia difusión", a punto tal que lo habían "visto en manos de médicos, estudiantes y literatos". Por esta vía, Payró había logrado "hacerles creer que, como asegura repetidamente Ferri, el marxismo es un complemento del spencerianismo". Para el Vorwärts, se trataba de una situación desgraciada, en tanto entendían que era "justamente Spencer quien provee hoy a la burguesía, cuando acaso esta todavía se enfrenta a nosotros con armas intelectuales, de sus más incisivos argumentos". El libro, en suma, no era "de valor ni utilidad para nuestra causa". ${ }^{47}$

La crítica que desenvolvía el Vorwärts abrevaba de forma evidente en el artículo de Kautsky aparecido en Die Neue Zeit, que era citado al inicio. El eje de la argumentación era señalar que la obra de Ferri no podía considerarse marxista y que por lo tanto se hacía un flaco favor a la causa de la clase obrera al promover su traducción y su difusión. El periódico de los socialistas alemanes en Buenos Aires argumentaba, como Kautsky, que “evidentemente, Ferri no ha leído ni El Capital de Marx ni el Dühring de Engels" y recordaba que el libro se apoyaba en las ideas de Achille Loria, una figura abiertamente cuestionada por la socialdemocracia alemana y por el propio Engels. Según el Vorwärts, Ferri se ubicaba

... en un terreno incierto, y su manía de querer encajar marxismo con spencerianismo lo lleva a afirmaciones y deducciones completamente antisocialistas, las cuales él luego, con increíble insolencia y estupidez, propone como marxismo. ${ }^{48}$

La "trinidad Darwin-Spencer-Marx", que constituía el subtítulo del libro de Ferri, era para los socialistas alemanes una combinación "absurda" y el resultado de una forma de pensar "completamente antimarxista" que pretendía ubicar como "ramas del mismo tronco" a la socialdemocracia alemana y a la burguesía radical. Sus ideas, en suma, no tenían "ninguna

\footnotetext{
${ }^{46}$ En un artículo publicado en Die Neue Zeit, Lallemant lamentaba que La Vanguardia publicara "frecuentemente traducciones de Ferri y Loria sin el menor criterio selectivo" sin aceptar "discusión sobre este asunto" (citado en Paso, op.cit., pág. 167).

47 “Der Sozialismus in Argentinien”, Vorwärts, núm. 456, 19 de octubre de 1895.

${ }^{48}$ Ibíd.
} 
relación con Marx" sino que se ubicaban en realidad en contacto "con ideas spencerianas y anarquistas". 49

Más allá de estos cuestionamientos generales, que apuntaban a rebatir la asimilación que hacía Ferri entre Marx y otros científicos de la época, el artículo del Vorwärts no entraba en una discusión más detallada de la obra del socialista italiano. Solo era criticada, siguiendo casi textualmente el escrito de Kautsky, la idea de Ferri según la cual los socialistas no combatían "a personas sino a sistemas". Los trabajadores socialdemócratas, recordaba el Vorwärts, sí combatían a individuos, "es decir a los terratenientes y a los capitalistas: no al agro y al capitalismo directamente, porque sin terratenientes ni capitalistas no existirían ni el agro ni el capitalismo, así como sin monarca no sería imaginable una monarquía". Siguiendo el mismo argumento, cuestionaban el completo rechazo que hacía Ferri de tácticas violentas y el papel que jugaron en la historia: "como opina muy acertadamente Kautsky, la toma de la Bastilla y la ejecución de Luis XVI fueron, sin duda, momentos mucho más significativos para la evolución social que alguna lucha electoral o alguna huelga ganada". 50

La conclusión era que el "socialismo de salón argentino" había encontrado "mucho placer en el libro de Ferri-Payró". Retomando los argumentos finales de Kautsky, el Vorwärts hacía referencias al origen social común de estos intelectuales que se acercaban al socialismo y otros miembros de la pequeña burguesía liberal y universitaria. "Quiera el círculo de lectores de la insípida "La Nation" [sic], donde, entre el tutti frutti presentado por este diario, el socialismo de salón juega un rol junto a la palabrería místico-religiosa y charlatanería positivista, deleitarse con la sabiduría de Ferri, sin embargo a los trabajadores hay que decirles claramente que eso no es ningún marxismo, ningún socialismo". 51

Para el Vorwärts, el libro de Ferri conducía a los lectores a Spencer, "es decir a la teoría de la burguesía radical, cerrándoles el camino a la conciencia de clases". Para evitarlo era necesario una polémica, y por ello en el número siguiente el periódico desarrollaba una crítica puntual de las ideas spencerianas. Los socialistas alemanes denunciaban allí nuevamente que Ferri metía "a Marx y a Spencer en la misma bolsa, sin conocer exactamente las teorías del primero" y llamaba a los trabajadores argentinos a no "dejarse engañar". La teoría de Spencer, según el Vorwärts, se "distancia[ba] irreconciliablemente" de Marx en tanto prohibía al Estado, "en nombre de la libertad de los individuos, cualquier intervención en la regulación de las relaciones entre los miembros de una sociedad". El socialismo, en cambio, requería "para todos los miembros de la sociedad la misma libertad e independencia de las que disfrutan los capitalistas y los poderosos", pero ello solo podía realizarse "cuando el Estado se haga cargo de la producción de bienes".

\footnotetext{
${ }^{49}$ Ibíd.

${ }^{50}$ Ibíd.

51 Ibíd.
} 
Para los socialistas alemanes, no todo era "una evolución espontánea, que surge de sí misma" sino que el desarrollo de la sociedad hacia formas más igualitarias requería una intervención de la voluntad y la lucha de los individuos. Spencer entendía al movimiento obrero "como un retroceso del sistema de la libertad al sistema de la sujeción, como la amenaza de la libertad por la mayoría", ignorando, según el Vorwärts, "que la mayoría deja de amenazar a la libertad cuanto más se suprimen los motivos del dominio de una clase sobre otra". 52

\section{La reivindicación de Justo y el peso de Ferri en los planteos del socialismo argentino}

Los artículos del Vorwärts se publicaron poco después del retorno de Justo a Buenos Aires, el 21 de septiembre de 1895, luego de una estadía de varios meses en Europa y en los Estados Unidos. Era un momento crítico: Eduardo García, que había jugado un rol predominante durante todo el año, había sido desplazado del periódico y de la agrupación, acusado de robo. Además, acababan de abrirse los registros cívicos para las elecciones legislativas de marzo del año siguiente, en el cual por primera vez se presentaría una lista socialista en la ciudad de Buenos Aires. En este escenario, Justo tomó inmediatamente un rol dirigente y puso todo su esfuerzo para orientar al naciente partido a darse una organización más firme. Retomó la redacción de La Vanguardia y publicó en las semanas y meses siguientes una importante cantidad de trabajos que reafirmaban la línea programática trazada desde la aparición del periódico, además de promover una serie de medidas de tipo organizativo que apuntaban a avanzar en la centralización de las fuerzas partidarias.

Fue en este marco que Justo creyó oportuno hacer, finalmente, una referencia a las críticas que el mismo Kautsky había realizado a la obra de Ferri. Su recorrido por Europa había sellado definitivamente la afiliación de Justo con el movimiento socialista internacional, pero al mismo tiempo había reforzado su interés en delimitarse de toda ortodoxia. Eso implicaba por supuesto evitar mostrar una afiliación directa con la socialdemocracia alemana, ${ }^{53}$ y en este sentido la valoración hecha por Justo acerca del libro de Ferri le daba el definitivo sello aprobatorio a su recepción en el país, reivindicando todo lo escrito en las páginas de La Vanguardia desde el año previo.

\footnotetext{
52 “Spencer und Ferri”, Vorwärts, 26 de octubre de 1895.

${ }^{53}$ Una carta enviada por Justo desde Bruselas, poco antes de su regreso, mostraba hasta qué punto lo habían impactado el socialismo belga en general y la figura de Emile Vandervelde en particular: "Yo creo que es en Bélgica donde se ha extendido el socialismo con un criterio científico más amplio y más práctico. Todo está organizado como para una campaña larga. Aquí es donde se ha hecho la primera única revolución socialista que hasta ahora haya tenido éxito: la huelga general de hace dos años en favor del sufragio universal. Y sin embargo nadie habla de revolución, ni de cambios violentos de la noche a la mañana". Sobre Vandervelde señalaba que: "no cree que la táctica socialista en Alemania y en Francia sea actualmente la mejor que se podría seguir (...) Es un orador correcto, claro, moderado, que parece creer lo que dice; la antítesis del demagogo charlatán. En todo sentido me ha gustado mucho" ("El socialismo en Bélgica", La Vanguardia, 10 de agosto de 1895).
} 
Lo hizo en un artículo sin firma, pero indudablemente salido de su pluma, que apareció en el último número de 1895. Allí, Justo reivindicaba la obra del socialista italiano y argumentaba que su mérito fundamental había sido articular satisfactoriamente al socialismo con la ciencia, y en particular con el darwinismo. Justo admitía que el libro podía tener "errores de detalle", pero entendía que globalmente había "venido a llenar una necesidad sentida". ${ }^{54} \mathrm{El}$ artículo hacía referencia explícita a las críticas aparecidas en Die Neue Zeit y en el Vorwärts, ${ }^{55}$ distanciándose abiertamente de ellas: La Vanguardia señalaba que "entre las dos grandes doctrinas, la biológica de Darwin y la sociológica de Marx, lejos de haber antagonismo, hay la más completa concordancia". Según Justo, Ferri había "consolidado los cimientos del socialismo teórico, probando que todo lo bueno que hay en las ideas de Spencer conduce a él, por más declaraciones en contrario que haga el mismo Spencer". "El concepto de la evolución de la sociedad", continuaba, "del estadio guerrero y autoritario al estadio industrial y libre, que ha tomado de Comte, es perfectamente aceptable por nosotros. La doctrina de la evolución de la inteligencia, y de la moral, son partes integrantes de toda teoría socialista completa".

Justo iba, de todas formas, aún más a fondo que los editores de La Vanguardia que habían reivindicado a Ferri en los meses previos y sacaba una serie de conclusiones de mayor alcance, vinculados con el abierto cuestionamiento del elemento dialéctico en la teoría socialista. En su artículo se planteaba el problema en los siguientes términos:

Marx era hegeliano. De Hegel tomó su concepto de la evolución, la teoría del werden. Pero Hegel fue un metafísico. Para nosotros, sus escritos son en gran parte incomprensibles. Su método dialéctico está abandonado. La norma intelectual del día es el método objetivo, el método positivo. Y en este método Spencer ha sido el maestro. Si la doctrina de la evolución universal se ha generalizado, es seguramente debido a Spencer, y no a Hegel, a quien hoy solo conocen los que estudian historia de la filosofía. Para explicar, o más bien dicho, designar el retorno de las instituciones y los organismos sociales a formas hace tiempo desaparecidas, recurre Marx a la negación de la negación, uno de los juegos de palabras de la metafísica hegeliana. Ahora eso nos parece rancio y oscuro, aunque sea Engels quien se encargue de explicárnoslo con su brillante facultad de exposición. ${ }^{56}$

En suma, la reivindicación del sincretismo ideológico aparecía como la principal contribución del libro de Ferri desde la perspectiva de Justo. El socialismo, "como doctrina social, necesitaba sobre todo una base económica e histórica" y el mérito de Marx y Engels era haberla provisto. Sin embargo, el "progreso científico" había continuado: "Darwin y sus precursores han revolucionado la teoría del mundo orgánico. Comte y Spencer han establecido definitivamente las bases del método". En este marco, "era necesario demostrar que ellos también han concurrido a sustentar la doctrina socialista, dándole una base

\footnotetext{
54 "Socialismo y ciencia positiva", La Vanguardia, 28 de diciembre de 1895.

55 "La obra de Ferri ha sido objeto de una crítica de Kautsky en la revista Die Neue Zeit, que ha inspirado otra más acerba en el Vorwärts de Buenos Aires".

56 "Socialismo y ciencia positiva", op.cit.
} 
biológica, y preparando las inteligencias para su triunfo final. Hacer esto ha sido el propósito del libro de Ferri, y haberlo hecho es su mérito". 57

Los artículos tempranos de Justo, por un lado, pero también la selección de aquello que se elegía traducir y publicar del socialismo internacional, por el otro, ya permiten advertir que la clave para entender su línea reformista era una explícita negación de la dialéctica. Si bien este es el punto central que, como ha señalado Kolakowski, representa el punto débil y la inconsistencia de Kautsky y el "centro ortodoxo" de la Internacional, en el caso del justismo se trató de un elemento mucho más decisivo, sobre todo porque era una crítica explícita y reivindicada abiertamente. En su conocido texto "El socialismo y Max Nordau", publicado a mediados de 1896, Justo retomaba los señalamientos hechos en su reivindicación del libro de Ferri y planteaba que

A lo que no conseguí meterle diente fue a eso que se enseña en los colegios nacionales bajo el nombre de filosofía; y sigo refractario a ello. Un amigo mío, que tiene la desgracia de creerse "materialista dialéctico", está empeñado en que yo soy materialista mecánico; pero yo no lo creo. No sé qué será eso, y me aflige pensar que pudiera alguna vez adornarme tal título, porque creería haber perdido algo que tiene la generalidad de los hombres: el sentido común. ${ }^{58}$

\section{Conclusiones}

En este artículo hemos rastreado la importancia que tuvo la difusión de Socialismo y ciencia positiva, de Enrico Ferri, en la estructuración política y programática del socialismo argentino a mediados de la década de 1890. La traducción y publicación de su obra fue una iniciativa de un grupo en particular, el de los jóvenes nucleados en el Centro Socialista Universitario, pero la promoción del folleto fue tomada sin reparos por La Vanguardia y promovida con numerosos artículos laudatorios en la prensa partidaria a lo largo de 1895. Tal como había sido ya señalado en la historiografía, la obra de Ferri permitió respaldar con el nombre de una figura de gran prestigio internacional a una línea política de orientación reformista y fuertemente tamizada por elementos positivistas que ya venía configurándose en los años previos.

La reivindicación de la obra de Ferri, de todos modos, estaba lejos de ser unánime en la socialdemocracia internacional de la época: en realidad, el núcleo mismo de la tradición marxista, la revista Die Neue Zeit, publicó en esas mismas fechas una abierta crítica de las ideas de Ferri en la pluma del propio Karl Kautsky. En este trabajo recuperamos ese artículo y reconstruimos los ejes fundamentales de esta crítica ortodoxa al socialismo de

\footnotetext{
${ }^{57}$ Ibíd.

58 “El socialismo y Max Nordau”, La Nación, 27 de junio de 1896. En términos de Javier Franzé, "Esta visión de la transformación social como un proceso evolutivo y progresivo tiene como sustento filosófico - términos que Justo hubiera rechazado - la sustitución del pensamiento negativo-dialéctico presente en Marx, por el modelo causal positivista, dentro del cual de todo elemento no puede sino derivarse más de lo mismo y nunca su contrario (...) De la fortaleza, en la óptica positivista, no puede surgir la debilidad, sino solo más fortaleza" (Franzé, El concepto de política en Juan B. Justo, op.cit., pág. 79).
} 
Ferri. Para Kautsky, el desarrollo de los movimientos obreros y socialistas se extendía con fuerza y de manera sostenida por toda Europa, bajo la influencia indiscutible de la socialdemocracia alemana, pero eso no implicaba que desarrollos similares se dieran al mismo ritmo en el plano teórico y programático. En ese terreno, era sin dudas la socialdemocracia alemana la que marcaba el paso, gracias a la influencia de Engels en los años posteriores a la muerte de Marx: su trabajo de crítica teórica había permitido, según Kautsky, superar el eclecticismo inicial y forjar una auténtica comprensión de las ideas marxistas. Era un proceso que aún se encontraba en curso en otros países, donde el eclecticismo primaba en el plano de las ideas e incluso se veía reforzado por la integración a las filas socialistas de intelectuales burgueses que no tenían una comprensión adecuada de las teorías de Marx. El trabajo de Ferri era un ejemplo de ello.

La importancia de recuperar esta obra de Kautsky reside no solo en que Die Neue Zeit era una indiscutible referencia para los socialdemócratas de todo el mundo durante este período sino también en que incluso en Buenos Aires la crítica tuvo una repercusión directa, dando lugar a una reseña crítica de la obra de Ferri en las páginas del Vorwärts. Como vimos, la argumentación de los socialistas alemanes de Buenos Aires seguía casi punto por punto el cuestionamiento hecho por Kautsky y ponía de relieve que existía, también en el seno del socialismo argentino, un debate en torno a la apropiación de las ideas de Ferri para la formulación programática del movimiento socialista local.

En este sentido, este artículo ha intentado mostrar no solo el trascendente impacto que tuvo el libro de Ferri en la estructuración de las definiciones programáticas del socialismo argentino, sino además que su recepción - así como el esfuerzo puesto en su difusiónestuvo lejos de ser ingenua. El debate ocasionado por el libro de Ferri en Europa era conocido en Buenos Aires: la reivindicación de las ideas de Ferri y su defensa frente a la crítica kautskiana — que era, al mismo tiempo, cuidadosamente soslayada en las páginas de La Vanguardia más allá de una referencia al pasar - fueron por lo tanto una decisión deliberada. ${ }^{59}$

La recepción de la obra de Ferri representó, en suma, una contribución importante para la estructuración del desarrollo político y teórico de la propuesta justista y su apología del eclecticismo: este artículo ha intentado mostrar que la misma emergió en el contexto de una serie de debates de alcance internacional en el seno de la socialdemocracia y que también en Argentina encontraron expresión una serie de críticas "ortodoxas" a la obra del socialista italiano, que sin embargo ocuparían más tarde un lugar marginal en la tradición partidaria.

\footnotetext{
59 "Dotti ha remarcado bien, en suma, que el problema central en la evaluación de la teoría de Justo no debe centrarse en su insuficiente conocimiento o en su 'incomprensión' de Marx y el marxismo sino en su decisión política de traducir los elementos cardinales de la doctrina socialista a un partido todavía incipiente” (Tarcus, Marx en la Argentina, op.cit., 384). También Aricó señala esta reivindicación del eclecticismo teórico como un rasgo característico del pensamiento de Justo, cuya "concepción de la doctrina socialista lo inclinaba a rechazar por principio cualquier tipo de ortodoxia teórica" (José Aricó, La hipótesis de Justo, op.cit., pág. 88).
} 


\section{Referencias}

Alves de Seixas, Jacy (1992) Mémoire et oubli: anarchisme et syndicalisme révolutionnaire au Brésil, mythe et histoire. Paris: Éd. de la Maison des sciences de l'homme.

Andreucci, Franco (1980) "La difusión y vulgarización del marxismo", en Historia del marxismo, Barcelona: Bruguera.

Andreucci, Franco y Tomasso Detti (1975) Il movimento operaio italiano: dizionario biografico, 1853-1943. Roma: Riuniti.

Aricó, José (1999) La hipótesis de Justo: escritos sobre el socialismo en América Latina, Buenos Aires: Sudamericana.

Bauer, Alfredo (2009) La Asociación Vorwärts y la lucha democrática en la Argentina. Buenos Aires: Biblioteca Nacional.

Blackledge, Paul (2002) "Historical Materialism: from Social Evolution to Revolutionary Politics", en Paul Blackledge y Graeme Kirkpatrick, Historical Materialism and Social Evolution. New York: Palgrave Macmillan.

Dotti, Jorge (1990) Las vetas del texto. Una lectura filosófica de Alberdi, los positivistas, Juan B. Justo, Buenos Aires: Puntosur.

Falcón, Ricardo (2011) “Orígenes del movimiento socialista en Argentina. Prólogo. Capítulo I y II”, Cuadernos del Ciesal, núm. 10, pp 11-45.

Ferri, Enrico (1895) Socialismo y ciencia positiva: Darwin, Spencer, Marx (traducción de Roberto J. Payró). Buenos Aires: Imprenta de la Nación.

Franzé, Javier (1993) El concepto de política en Juan B. Justo. Buenos Aires: Centro Editor de América Latina.

Geli, Patricio y Leticia Prislei (1993) "Una estrategia socialista para el laberinto argentino. Apuntes sobre el pensamiento político de Juan B. Justo”, Entrepasados, núm. 4-5.

Herrera, Carlos (2015) "El socialismo argentino frente a Enrico Ferri”, Archivos de historia del movimiento obrero y la izquierda, núm. 6, pp. 73-94.

Hobsbawm, Eric (1983) "La difusión del marxismo (1890-1905)", en Marxismo e historia social, Puebla: Instituto de Ciencias de la Universidad Autónoma de Puebla.

Kautsky, Karl (1895) “Marxismus und Darwinismus”, Die Neue Zeit, vol. 13 (tomo 1), núm. 23, pp. 709-716.

Klima, Jan (1974) "La asociación bonaerense Vorwärts en los años ochenta del siglo pasado", Iberoamericana Pragensia, vol. VIII.

Kolakowski, Leszek (1978) Main Currents of Marxism: Its Rise, Growth, and Dissolution. Oxford: Clarendon Press.

Martínez Mazzola, Ricardo (2011) "El debate Justo-Ferri y la cuestión de las alianzas políticas", Revista Socialista, núm. 5, pp. 63-74. 
Paso, Leonardo (1974) La clase obrera y el nacimiento del marxismo en la Argentina. Buenos Aires: Anteo.

Poy, Lucas y Daniel Gaido (2011) "Under German Eyes: German Ave-Lallemant and the Origins of Marxism in Argentina”, Science \& Society, vol. 75, núm. 4, pp. 480-505.

Poy Lucas (2014) Los orígenes de la clase obrera argentina. Buenos Aires: Imago Mundi.

Rafferty, Catherine (1990) "Karl Kautsky, between Darwin and Marx", Australian Journal of Politics and History, 38, pp. 377-387.

Ratzer, José (1970) Los marxistas argentinos del 90, Córdoba: Pasado y Presente.

Salvadori, Rinaldo (1960) "Enrico Ferri politico. Dal radicalismo all'adesione al Partito Socialista”, Rivista Storica del Socialismo, núm. 11, pp. 499-543.

Salvadori, Rinaldo (1966) La repubblica socialista mantovana. Da Belfiore al fascismo. Milán: Del Gallo.

Stack, David (2003) The First Darwinian Left. Socialism and Darwinism, 1859-1914. Cheltenham: New Clarion Press.

Steenson, Gary (1979) Karl Kautsky 1854-1938. Marxism in the Classical Years. Pittsburgh: University of Pittsburgh Press.

Tarcus Horacio (2007) Marx en la Argentina. Sus primeros lectores obreros, intelectuales y científicos, Buenos Aires: Siglo XXI.

Tarcus, Horacio, Jessica Zeller y Sandra Carreras (2008) Los socialistas alemanes y la formación del movimiento obrero argentino: Antología del Vorwärts, (1886 - 1901). Buenos Aires: CeDInCI Editores/Buenos Libros.

Walter, Richard (1977) The Socialist Party of Argentina, 1890-1930. Austin: The University of Texas Press.

Weikart, Richard (1998) Socialist Darwinism: Evolution in German Socialist Thought from Marx to Bernstein. San Francisco: International Scholars Publications.

Zeller, Jessica (2007) "Entre la tradición y la innovación. La experiencia del Vorwärts en Buenos Aires", Políticas de la memoria, núm. 5. 